\title{
Conservation implications of avian malaria exposure for African penguins during rehabilitation
}

AUTHORS:

Annelise Botes ${ }^{1}(D)$

Hanlie Thiart ${ }^{1}$

Nola J. Parsons ${ }^{2,3}$

Dirk U. Bellstedt ${ }^{1}$

\section{AFFILIATIONS:}

'Department of Biochemistry,

Stellenbosch University,

Stellenbosch, South Africa

${ }^{2}$ Southern African Foundation

for the Conservation of Coastal

Birds, Cape Town, South Africa

${ }^{3}$ Bayworld Centre for Research and Education, Port Elizabeth,

South Africa

\section{CORRESPONDENCE TO:}

Annelise Botes

\section{EMAIL:}

annelise@sun.ac.za

\section{DATES:}

Received: 14 Aug. 2016

Revised: 20 Dec. 2016

Accepted: 15 Feb. 2017

\section{KEYWORDS:}

Plasmodium; antibody response; ELISA; SANCCOB; vector control

\section{HOW TO CITE:}

Botes A, Thiart H, Parsons NJ, Bellstedt DU. Conservation implications of avian malaria exposure for African penguins during rehabilitation. S Afr J Sci. 2017;113(7/8), Art. \#2016-0244, 8 pages. http://dx.doi.org/10.17159/ sajs.2017/20160244

\section{ARTICLE INCLUDES:}

$\checkmark$ Supplementary material

$\times$ Data set

FUNDING:

World Wildlife Fund (South Africa)
The African penguin (Spheniscus demersus) is the only penguin species that breeds on the African continent and it is currently classified as endangered. Its conservation is assisted by the Southern African Foundation for the Conservation of Coastal Birds (SANCCOB) which is a seabird rehabilitation facility based at the Rietvlei Wetland Reserve in Tableview, Cape Town. Despite the success of SANCCOB in rehabilitating diseased, injured or oiled penguins, significant mortalities have occurred at the facility as a result of avian malaria. Avian malaria can be contracted during rehabilitation during which penguins are inadvertently exposed to additional threats. An enzyme-linked immunosorbent assay (ELISA) was used to assess the anti-Plasmodium antibody levels of penguins to avian malaria on entry into the SANCCOB facility from 2001 to 2004 and during their rehabilitation process. Using blood smear data, avian malaria prevalence and malaria-related deaths were also monitored from 2002 to 2013. Significant increases in anti-Plasmodium antibody levels after admission were found during summer months. New infection and not parasite recrudescence was concluded to be the cause of this increase. This source was confirmed by a dramatic drop in penguin mortalities upon exclusion of mosquito vectors in 2008. Mortalities did not depend on the birds' abilities to produce an anti-Plasmodium antibody response and oiling had no influence on immunity or prevalence of avian malaria infections. This study highlights the importance of mosquito vector control to control pathogen exposure in wild bird rehabilitation centres.

\section{Significance:}

- Efforts to assist with the conservation of endangered species can unintentionally add to the conservation burden.

- Rehabilitation influences exposure of African penguins to avian malaria.

- Avian malaria prevalence and mortality are not influenced by oiling or anti-Plasmodium antibody responses.

- Vector control can limit avian malaria exposure in wild bird rehabilitation centres.

\section{Introduction}

The African penguin (Spheniscus demersus) is the only penguin species that breeds on the African continent. Their numbers have decreased from an estimated 1.5-3 million before 1900 to fewer than 26000 breeding pairs in $2009^{1,2}$ - a decline which has resulted in their conservation status being changed from vulnerable to endangered ${ }^{2}$. Since the late 1800 s, a sequence of threats has led to their decline. Breeding habitats were reduced through guano collection, followed by egg collection for human consumption, overexploitation of prey species and, recently, oiling events caused by oil spills. ${ }^{1}$ Furthermore, blood parasites such as Plasmodium, which causes avian malaria, are ongoing threats leading to further mortalities. ${ }^{3,4}$

The Southern African Foundation for the Conservation of Coastal Birds (SANCCOB) maintains a seabird rehabilitation facility based at the Rietvlei Wetland Reserve in Tableview, Cape Town. They rehabilitate diseased, injured or oiled seabirds, of which most are African penguins. Through SANCCOB's efforts, African penguins have been able to survive in the wild after release and have successfully returned to breeding. ${ }^{5}$ Unfortunately, avian malaria infections and associated mortalities in African penguins do occur at the facility.

Internationally, avian malaria is a known cause of mortality in captive penguins kept in outdoor displays or zoos with $P$. relictum and $P$. elongatum being the associated parasites.$^{6-10}$ In the case of wild birds, $P$. tejerai, $P$. cathemerium, $P$. nucleophilum and $P$. unalis could be identified in Magellanic penguins (S. magellanicus) undergoing rehabilitation along the coast of Brazil. ${ }^{11}$ The first report of a Plasmodium infection in an African penguin in the wild was from Saldanha Bay, described as $P$. relictum subsp. spheniscidae. ${ }^{12}$ Brossy et al. ${ }^{4}$ identified $P$. relictum in wild African penguins being rehabilitated at $\mathrm{SANCCOB}$, but rarely found parasitaemia in penguins at their breeding colonies. These findings were based on blood smear analysis; when using anti-Plasmodium antibody levels as an indicator of avian malaria exposure, both wild and captive African penguins were found to be exposed to avian malaria.,13 In addition, about $30 \%$ of penguins admitted to SANCCOB were already malaria positive based on blood smear analysis, on entry into the facility, indicating exposure of the wild population to the pathogen. ${ }^{3}$ It was subsequently suggested that wild and captive penguins were being exposed to different Plasmodium species ${ }^{4}$ which could explain the higher levels of infection and mortality experienced during rehabilitation. ${ }^{3,13}$ In captivity, there is an increased chance of being exposed to mosquito vectors that could act as a reservoir for land bird avian malaria parasites. ${ }^{14,15}$

The impact of avian malaria on the decline of wild avian populations is best illustrated by the history of native Hawaiian bird species. Examples are the the Hawaiian crow, or Alalã (Corvus hawaiiensis), which is now extinct in the wild ${ }^{16}$, and the Hawaiian honeycreepers (Drepanidinae) of which most species are either extinct or critically endangered ${ }^{17}$. In the case of the Galápagos penguin (S. mendiculus), the introduction of Plasmodium to the Galápagos Islands is causing concern about the effect this introduction will have on the survival of this endangered species. ${ }^{18}$ Because seabirds breed in relatively small geographical areas, they are sensitive to environmental changes, with 
population declines as a possible consequence. ${ }^{19}$ Population declines in turn increase the vulnerability to diseases..$^{20}$ As a result, there is a need for dedicated rescue and rehabilitation centres that play a significant role in ensuring the conservation of species, but they could inadvertently be exposing animals to new threats. ${ }^{21}$ The possibility of introducing a foreign avian malaria parasite into African penguins during rehabilitation is therefore a major concern, as subsequent introduction into wild breeding populations could cause a further decline in an already endangered seabird population.

During rehabilitation at SANCCOB, efficient treatment of avian malaria requires early diagnosis, because it is often too late for treatment once clinical signs appear. Screening for blood parasites is therefore conducted through routine blood smear evaluation, but serious pathological effects and even death can occur prior to the appearance of parasites in circulating erythrocytes. ${ }^{22}$ The lack of parasites in erythrocytes also does not exclude their possible presence in the endothelium or haemopoietic tissue. ${ }^{6,7,23}$ Furthermore, Babesia infections cannot easily be distinguished from Plasmodium infections by blood smear. ${ }^{24}$ The polymerase chain reaction (PCR) can be used as an alternative diagnostic technique as it is viewed to be more sensitive and highly specific and does not rely on visualisation of the parasite..$^{25}$ Unfortunately, similarly to blood smears, the method relies on the presence of circulating blood parasites $^{26}$ and therefore these methods are not always a true reflection of parasite exposure ${ }^{13,26}$.

On the basis of cross-reactivity between anti-Plasmodium antibodies, Graczyk et al. ${ }^{23}$ developed an enzyme-linked immunosorbent assay (ELISA) for the detection of anti-P. relictum and anti-P. elongatum antibodies. It was found to be an effective tool for diagnosing exposure to avian malaria in penguins. ${ }^{27}$ The ELISA made use of a recombinant polypeptide $\left(\right.$ R32tet $\left._{32}\right)$ as capture antigen, which consisted of 32 tetrapeptides - 31 with the sequence NANP and 1 with the sequence NVDP followed by a 32 amino acid hydrophobic tail. ${ }^{28}$ The sequence was derived from the highly immunogenic repeat region of the circumsporozoite (CS) protein of $P$. falciparum. CS-proteins are uniformly distributed over the entire membrane surface of sporozoites, which is the first stage of the parasite in the avian host after being infected. Immunological cross-reactivity is known to exist against the CS-proteins of unrelated species and this may be as a result of structural and functional similarities of the secondary and tertiary structures resulting in common epitopes. ${ }^{23,29-31}$

The objectives of this study were, firstly, to evaluate the exposure of wild African penguins to avian malaria during rehabilitation at SANCCOB by measuring anti-Plasmodium antibody levels using an ELISA similar to that of Graczyk et al. ${ }^{23}$; secondly, to determine the influence of these antibody levels on survival during rehabilitation and the effect of oiling on antibody levels and, finally, to show the effect of vector exclusion on the incidence of malaria-related deaths at SANCCOB.

\section{Materials and methods}

\section{Sample collection and processing}

Anti-Plasmodium antibody levels of African penguins upon entry to the SANCCOB facility, and for up to 3 weeks after admission, were assessed in birds admitted from October 2001 to January 2004. Penguins were admitted for various reasons such as oiling, poor condition, injury, abandonment or arrested moulting. No specific age group was targeted.

As part of SANCCOB's health monitoring procedures, ${ }^{3}$ weekly blood samples were routinely taken from all penguins present in the rehabilitation facility for blood smear analysis. Sampling of blood entailed insertion of a 23-gauge needle into the intradigital foot vein of a penguin and collection into a heparinised capillary tube. Thin blood smears were prepared immediately after blood collection and slides were fixed with methanol and stained with a modified Wright-Giemsa stain (Kyron Laboratories, Johannesburg, South Africa). For antibody analysis, a single $50 \mathrm{~mL}$ blood volume, as measured by calibrated heparinised capillary tubes, was deposited on filter paper (Immunovet Services, Johannesburg, South Africa) and air dried. ${ }^{27}$ Prior to ELISA testing, blood was eluted overnight at $4{ }^{\circ} \mathrm{C}$ from each of the filter papers with $333.33 \mathrm{~mL}$ Millipore water containing $0.4 \%$ Tween $20 .{ }^{23}$

Birds were rehabilitated and released as soon as deemed fit to survive in the wild. ${ }^{3}$ Consequently, there was a difference in the number of data points collected for each bird. The aim was to obtain at least 30 samples per week and therefore released birds were replaced with newly admitted birds, unless fewer birds were actually being rehabilitated, at any given time.

Positive and low or negative control sera were obtained from the routine blood samples. The positive control was from a penguin that tested malaria positive on blood smear and had a high anti-Plasmodium antibody titre in our ELISA. The negative control was from a penguin chick that was artificially hatched and raised in a vector-free environment before being admitted to SANCCOB for rehabilitation.

\section{ELISA capture antigen}

Ballou et al. ${ }^{32}$ synthesised peptides containing 8-16 residues of the CS-protein repeat region of $P$. falciparum containing the sequence NANP. Antibodies against these peptides were able to recognise native CS-protein and therefore a peptide with the sequence (NANP) ${ }_{4}$ was used as capture antigen in this study. To allow for conjugation to bovine serum albumin (BSA) the peptide was synthesised containing a S-acetylmercaptosuccinic anhydride (SAMSA) group coupled to its $\mathrm{N}$-terminal side. Synthesising the SAMSA-peptide (Biopep Laboratories, Stellenbosch University, Stellenbosch, South Africa) allowed the preparation of a capture antigen free of contaminating serum proteins that could cause cross-reactions in the ELISA. The purity of the peptide was confirmed by electrospray mass spectrometry analysis.

Prior to use, the peptide was conjugated to BSA in a 3:1 ratio to allow for a more rigid attachment of the peptide to the polystyrene surface of the microtitre plate. ${ }^{33}$ This step prevents desorption of antigen during ELISA incubation and wash steps. Conjugation consisted of three reaction steps: the introduction of maleimide groups into BSA, introduction of a sulfhydryl group into the malaria peptide and conjugation of the malaria peptide to the activated BSA. ${ }^{34-38}$ To ensure that the peptideBSA conjugate solution was not contaminated with smaller or larger complexes, it was subjected to gel filtration chromatography using a G-25 Sephadex column.

\section{Penguin anti-Plasmodium antibody ELISA}

Microtitre plates (96 well, MediSorp ${ }^{\mathrm{TM}}$, Thermo Scientific ${ }^{\mathrm{TM}}$, Nunc ${ }^{\mathrm{TM}}$, Roskilde, Denmark) were coated overnight at $4{ }^{\circ} \mathrm{C}$ with $0.5 \mathrm{mg} / \mathrm{mL}$ (100 mL/well) of the 3:1 peptide-BSA conjugate in carbonate buffer (50 mM, pH 9.6). The coating solution was decanted and the plate blocked $\left(1 \mathrm{~h}, 37^{\circ} \mathrm{C}\right)$ with casein buffer $(0.5 \%$ casein, $0.15 \mathrm{M} \mathrm{NaCl}, 0.01$ M Tris-HCl, $0.02 \%$ thiomersal, pH 7.6, $200 \mathrm{~mL} /$ well). Filter paper eluates were diluted $1 / 50$ and serum $1 / 200$ in casein buffer containing $0.1 \%$ Tween 20 (casein-Tween), added to wells in triplicate $(100 \mathrm{~mL} /$ well) and incubated $\left(3 \mathrm{~h}, 37^{\circ} \mathrm{C}\right)$. Biotinylated rabbit anti-penguin Ig antibody was prepared as described ${ }^{33}$ and added $(100 \mathrm{~mL} /$ well) after being diluted $1 / 100$ in casein-Tween. After incubation $\left(1 \mathrm{~h}, 37^{\circ} \mathrm{C}\right)$, avidin-horseradishperoxidase conjugate (Zymed ${ }^{\circledR}$, San Francisco, CA, USA) diluted 1/100 in casein-Tween was added (100 mL/well) and the plates were further incubated $\left(1 \mathrm{~h}, 37^{\circ} \mathrm{C}\right)$. Finally, the substrate solution (ABTS, $0.015 \%$ $\mathrm{H}_{2} \mathrm{O}_{2}$ in $0.1 \mathrm{M}$ citrate buffer, $\mathrm{pH} 5,100 \mathrm{~mL} /$ well) was added and the absorbance measured after $30 \mathrm{~min}$ at $37^{\circ} \mathrm{C}$ on a Labsystems Multiskan MS spectrophotometer at $405 \mathrm{~nm}$. Between all steps, the plates were washed three times, except after coating, with phosphate-buffered saline (PBS; $200 \mathrm{~mL} /$ well) containing $0.1 \%$ Tween 20,. Negative and positive control sera were included on each plate to monitor inter-assay variation. The ability of the capture antigen to distinguish between malaria positive and negative sera as well as non-specific reactions towards activated BSA were also evaluated. 


\section{Data analysis}

ELISA data from October 2001 to January 2004 were grouped together into 2-month periods. Because penguins were being admitted continuously within a specific 2-month period, the week of entry for all penguins in that period was taken as Week 0 and subsequent weeks of sampling as Weeks 1 and 2.

The absorbance values measured during ELISA analysis are referred to as ELISA titres which represent anti-Plasmodium antibody levels. The change in antibody levels, one and two weeks after admission, were calculated for each 2-month period. This calculation was done by subtracting the average titre value obtained at Week 0 from that obtained at Week 1 and again at Week 2. The resulting two values were plotted graphically for each 2-month period.

Most penguins were rehabilitated for no longer than 2-3 weeks after admission and therefore only the data for Weeks 0,1 and 2 were used for statistical analysis using the general linear models procedure in the Statistical Analysis System (SAS) Enterprise Guide (version 1.3.0.161). Weather data were obtained from Weather Underground and Harris et al. ${ }^{39}$

\section{Monitoring the prevalence of avian malaria}

The prevalence of avian malaria (number of samples positive during rehabilitation divided by the number of individual bleeds) was also determined for the facility as a whole. This determination was based on blood smear analysis which is routinely performed and therefore allowed for long-term monitoring (2002-2013). Plasmodium diagnosis was based on identification of trophozoites and gametocytes in the erythrocytes with the latter used to distinguish from Babesia infections. Meronts were rarely identified. Deaths that occurred as a result of avian malaria were confirmed during post-mortem examinations as described. ${ }^{40}$

\section{Results}

Penguin anti-Plasmodium antibody ELISA

Gel filtration chromatography produced a single peak indicating that the conjugate consisted of a single complex (Supplementary figure 1). ELISA titres of positive and negative penguin serum samples indicated that anti-Plasmodium antibodies were able to cross-react with the peptide-BSA conjugate (Supplementary figure 2) and this interaction was primarily aimed at the peptide.

\section{Anti-Plasmodium antibody response}

The increase in anti-Plasmodium antibody levels after admission to the SANCCOB facility is shown in Figure 1. In penguins admitted from October to November 2001, an increase in antibody levels could only be observed by Week 2. In penguins admitted from December 2001 to January 2002, there was an earlier increase in antibody levels one week after entering the facility and this pattern continued for penguins admitted during the warmer months until March 2002. This period coincided with an increase in the number of birds that tested positive for malaria by blood smear during rehabilitation (Table 1). As ambient temperatures started to drop, so did the increase in antibody responses one week after admission as well as the percentage of penguins that tested blood smear positive $(\mathrm{BS}+)$. Antibody levels started to increase again after admission during October-November 2002, but at much lower levels than those during 2001. A more pronounced increase in antibody levels, however, followed during February-May 2003 compared to the same period in 2002, but this increase did not coincide with an increase in BS+ penguins (Table 1). The elevation in antibody levels in 2003 again decreased as temperatures dropped (June-July), and then increased slightly as temperatures started to increase (August-September), but BS + cases during rehabilitation only started to increase after the August-September 2003 period. Analysis indicated a significant association between the average increase in ELISA titre values 2 weeks after admission and average day $(p=0.028)$ and night $(p=0.008)$ temperatures (see the supplementary material).

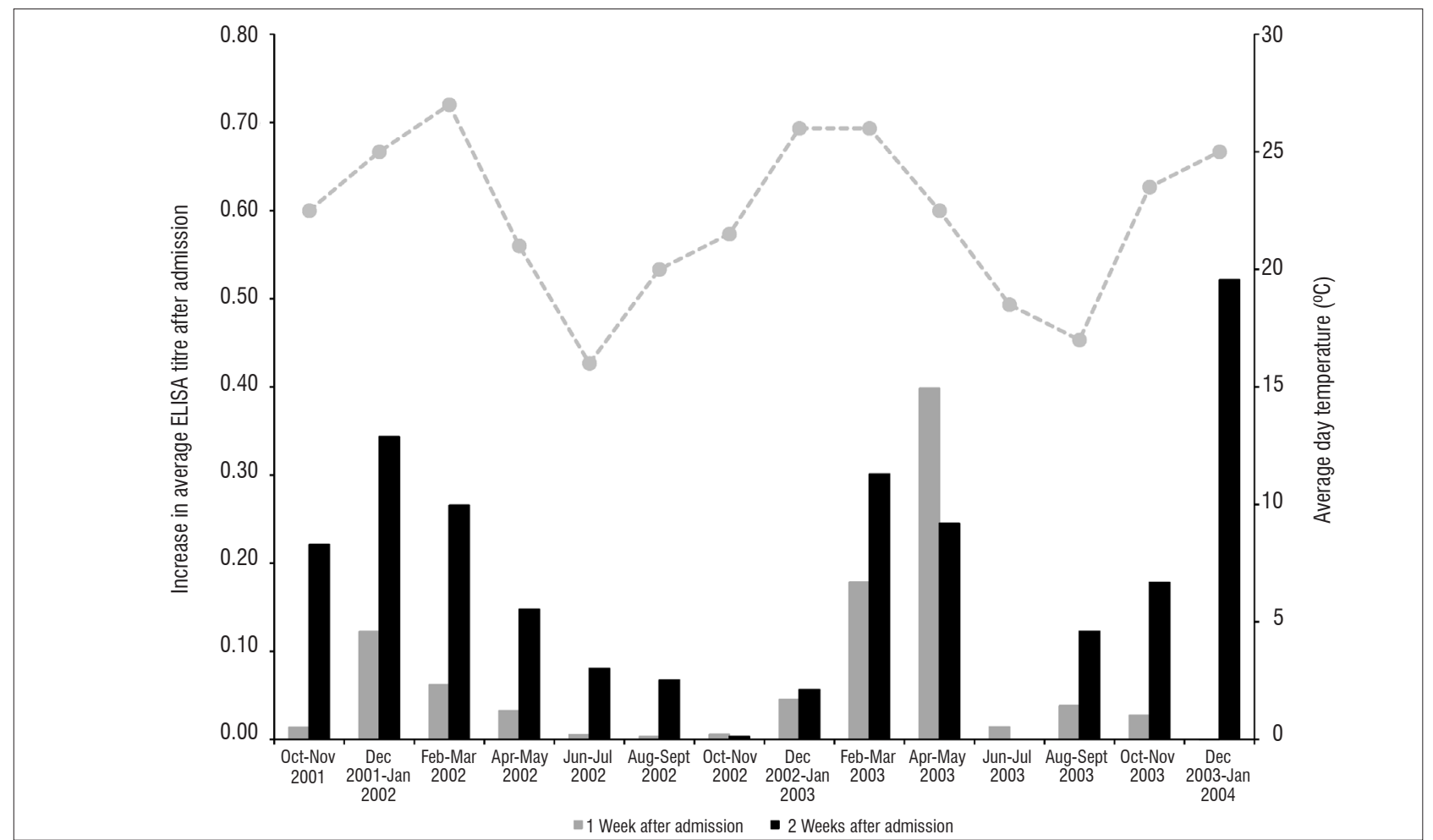

Figure 1: Increases in anti-Plasmodium antibody levels in the weeks after entry into the SANCCOB facility: '1 Week after admission' represents the difference in average ELISA titre values from Week 0 to Week 1 ; '2 Weeks after admission' represents the difference in average ELISA titre values from Week 0 to Week 2. The temperature is the average maximum values for a given 2-month period. 
Table 1: Avian malaria blood smear data for African penguins that were eventually released and for those that died during rehabilitation at SANCCOB

\begin{tabular}{|c|c|c|c|c|c|c|c|c|c|c|c|c|c|c|c|}
\hline & & 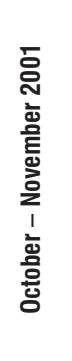 & 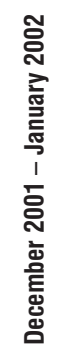 & 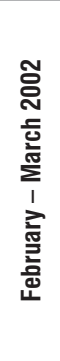 & 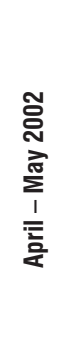 & 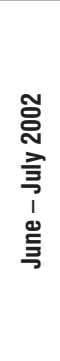 & 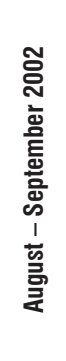 & 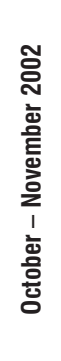 & 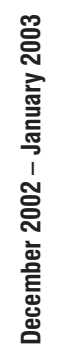 & 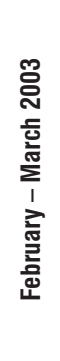 & 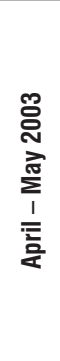 & 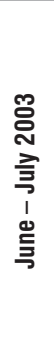 & 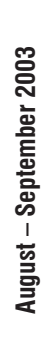 & 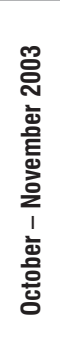 & 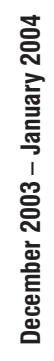 \\
\hline \multirow[b]{2}{*}{ All } & $n$ & 52 & 48 & 10 & 66 & 51 & 61 & 42 & 32 & 37 & 53 & 70 & 82 & 64 & 54 \\
\hline & BS+ & $59 \%$ & $70 \%$ & $50 \%$ & $16 \%$ & $9 \%$ & $14 \%$ & $21 \%$ & $38 \%$ & $18 \%$ & $13 \%$ & $8 \%$ & $6 \%$ & $26 \%$ & $22 \%$ \\
\hline \multirow{2}{*}{ Released after rehabilitation } & $n$ & 36 & 25 & 6 & 59 & 46 & 59 & 35 & 24 & 27 & 50 & 68 & 80 & 53 & 42 \\
\hline & BS+ & $53 \%$ & $48 \%$ & $50 \%$ & $12 \%$ & $9 \%$ & $15 \%$ & $14 \%$ & $38 \%$ & $11 \%$ & $12 \%$ & $9 \%$ & $6 \%$ & $21 \%$ & $14 \%$ \\
\hline \multirow[b]{3}{*}{ Died during rehabilitation } & $n$ & 16 & 23 & 4 & 7 & 5 & 2 & 7 & 8 & 10 & 3 & 2 & 2 & 11 & 12 \\
\hline & BS+ & $75 \%$ & $96 \%$ & $50 \%$ & $57 \%$ & $20 \%$ & $0 \%$ & $57 \%$ & $38 \%$ & $40 \%$ & $33 \%$ & $0 \%$ & $0 \%$ & $55 \%$ & $50 \%$ \\
\hline & $\begin{array}{l}\text { Malaria- } \\
\text { specific } \\
\text { death }^{*}\end{array}$ & $75 \%$ & $96 \%$ & $50 \%$ & $57 \%$ & $20 \%$ & $0 \%$ & $57 \%$ & $38 \%$ & $20 \%$ & $33 \%$ & $0 \%$ & $0 \%$ & $55 \%$ & $50 \%$ \\
\hline
\end{tabular}

$B S+$, blood smear positive

*percentage of total number that died during rehabilitation

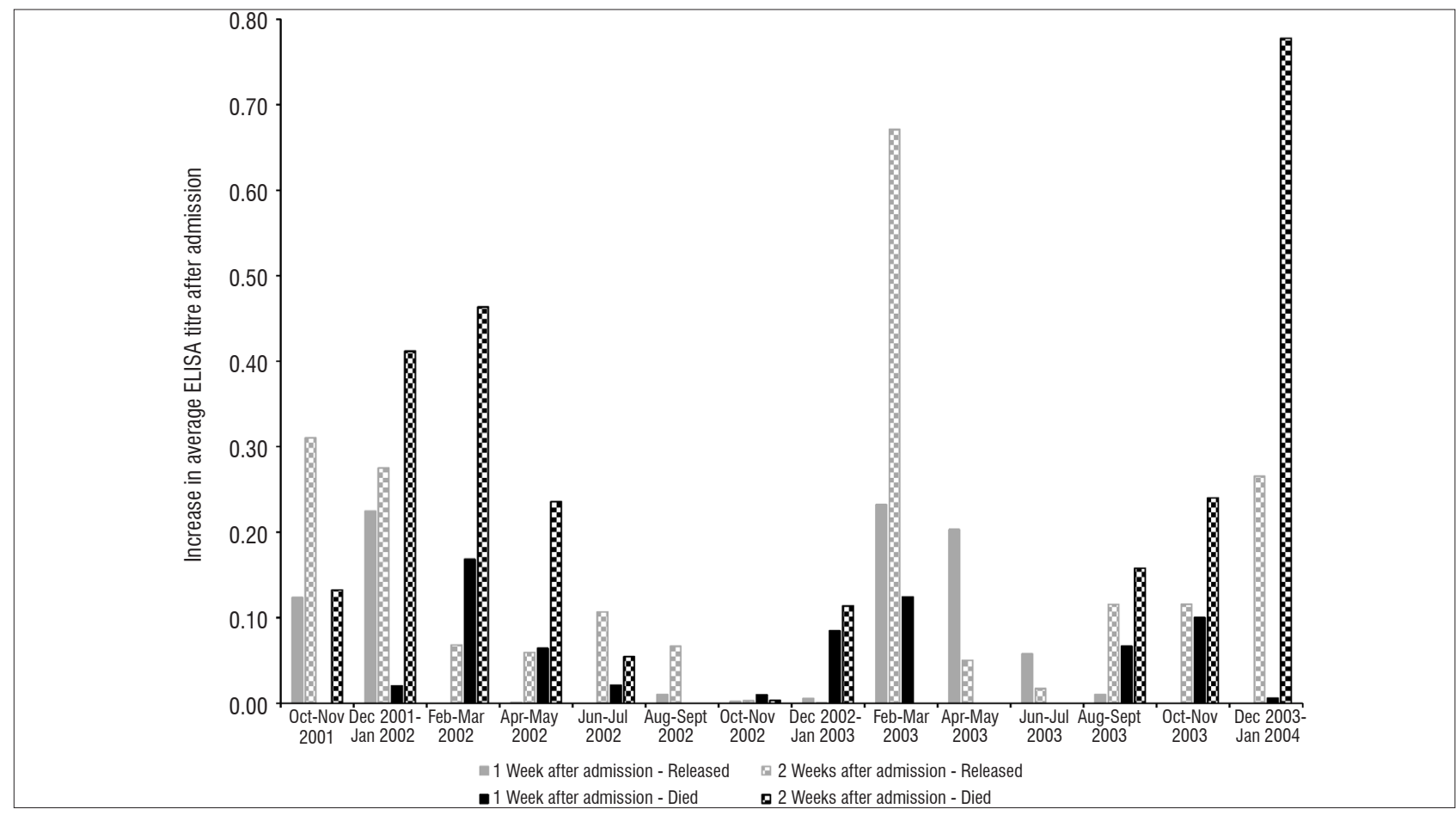

Figure 2: Increases in anti-Plasmodium antibody levels of penguins that were released compared with those that died after entry into the SANCCOB facility: '1 Week after admission' represents the difference in average ELISA titre values from Week 0 to Week 1; '2 Weeks after admission' represents the difference in average ELISA titre values from Week 0 to Week 2. No deaths were recorded during April-May 2003. Missing data points for other months reflect no increases in titre values.

\section{Influence of anti-Plasmodium antibody response on survival}

The increase in anti-Plasmodium antibody levels in penguins that were released and those that died during rehabilitation are shown in Figure 2. Although these data indicated that the penguins were responding to Plasmodium infections by producing an antibody response, the difference in response between the released and deceased penguins was not statistically significant.
Malaria blood smear data for the penguins that were released vs those that died for each of the respective 2-month periods are shown in Table 1 along with the percentage of deaths as a result of malaria as confirmed by post-mortem examination. All penguins that died during rehabilitation as a result of malaria were also those that tested BS+ for malaria resulting in the percentage BS+ cases and malaria deaths being the same. The only exception was the birds sampled in February-March 2003, for which not all deaths were as a result of malaria - only $20 \%$ were malaria-related deaths. 


\section{Influence of oiling on the anti-Plasmodium antibody response}

The effect of oiling on the increase in anti-Plasmodium antibody levels is shown in Figure 3. No statistically significant difference was found between oiled and not oiled penguins except for the period December 2001 to January 2002. The significant difference $(p=0.0136)$ is, however, questionable as there were only four oiled penguins during this period and the difference was caused by the high titre of a single penguin that was oiled and that died during rehabilitation.

Malaria blood smear results of the oiled versus not oiled penguins during rehabilitation and the number of penguins that died as a result of malaria are shown in Table 2. The number of birds that tested positive for malaria by blood smear and that died as a result of malaria during rehabilitation were on average higher in the not oiled group.

\section{Monitoring the prevalence of avian malaria}

The prevalence of avian malaria and the deaths specifically related to avian malaria at SANCCOB in the period from 2002 to 2013 are shown in Table 3. These data show a persistent level of avian malaria infection in penguins being rehabilitated during the period from 2001 to 2008 . There is, however, not always a good correlation between avian malaria prevalence and malaria-specific deaths, which indicates the inefficiency of blood smear analysis as a diagnostic tool. A mosquito-proof net was installed over the open-air part of the facility in October 2008, after which there was a sharp decrease in the prevalence of and deaths as a result of avian malaria.

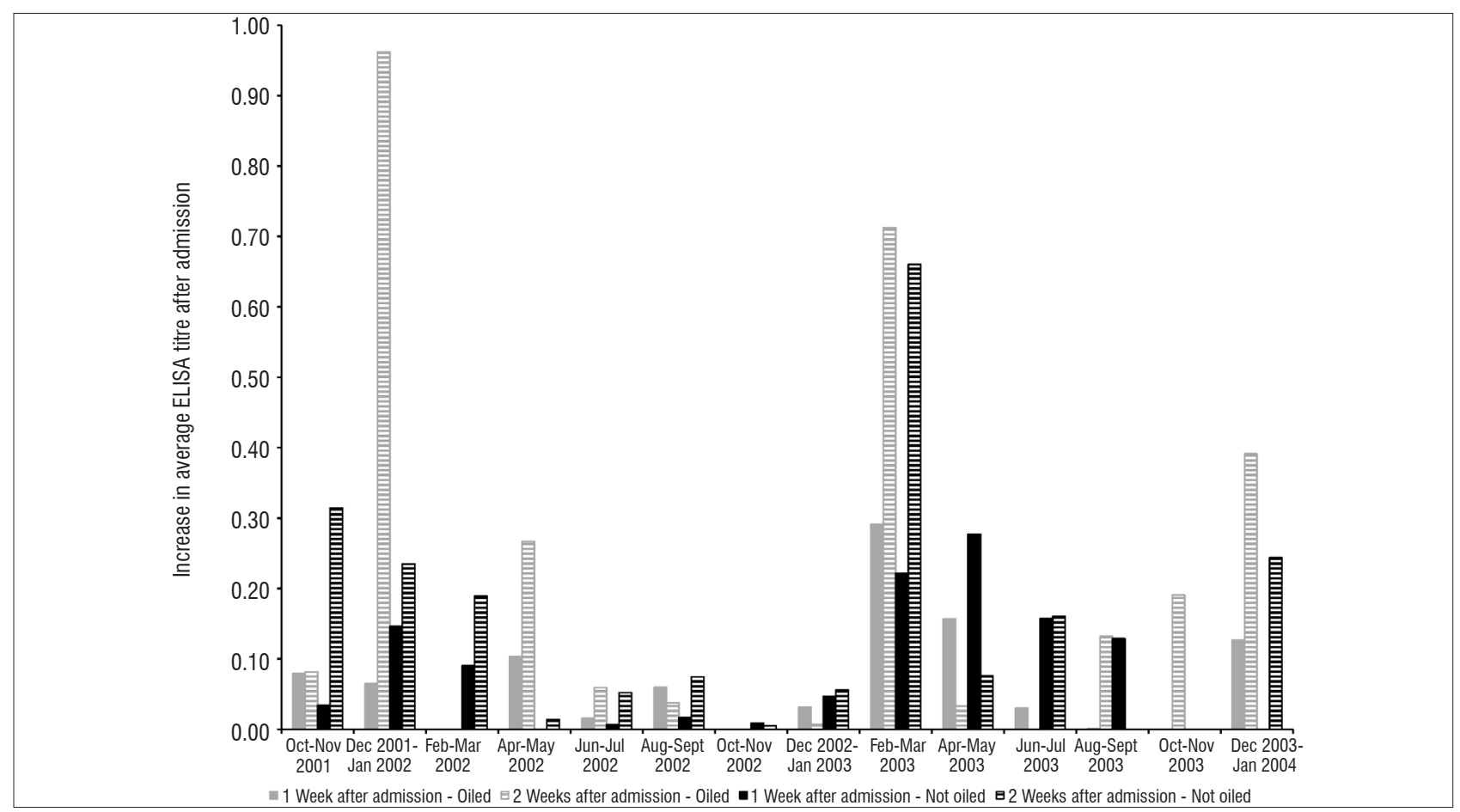

Figure 3: Increases in anti-Plasmodium antibody levels of penguins that were oiled compared with those that were not oiled upon entry into the SANCCOB facility: '1 Week after admission' represents the difference in average ELISA titre values from Week 0 to Week 1; '2 Weeks after admission' represents the difference in average ELISA titre values from Week 0 to Week 2. There were no oiled penguins during February-March 2002. Missing data points for other months reflect no increases in titre values.

Table 2: Avian malaria blood smear data during rehabilitation for African penguins that were oiled and not oiled on admission

\begin{tabular}{|c|c|c|c|c|c|c|c|c|c|c|c|c|c|c|c|}
\hline & & 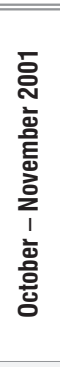 & 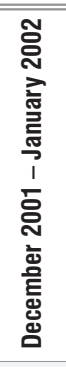 & 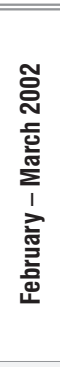 & 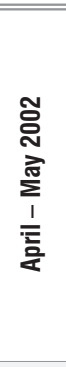 & 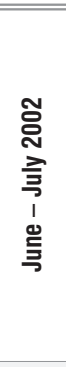 & 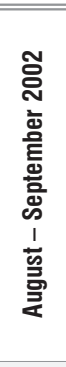 & 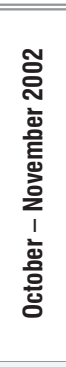 & 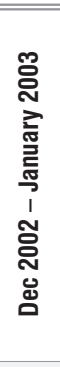 & 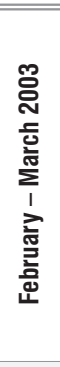 & 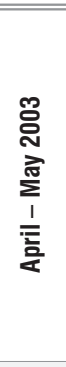 & 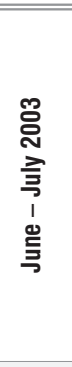 & 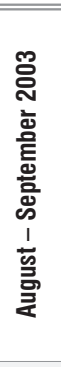 & 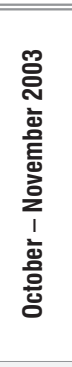 & 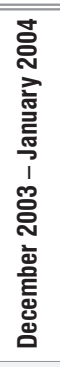 \\
\hline All & $n$ & 52 & 48 & 10 & 66 & 51 & 61 & 42 & 32 & 37 & 53 & 70 & 82 & 64 & 54 \\
\hline \multirow{3}{*}{ Oiled } & $n$ & 20 & 7 & 0 & 41 & 43 & 46 & 19 & 4 & 5 & 35 & 55 & 70 & 40 & 28 \\
\hline & BS+ & $45 \%$ & $71 \%$ & $0 \%$ & $12 \%$ & $7 \%$ & $9 \%$ & $11 \%$ & $75 \%$ & $20 \%$ & $6 \%$ & $4 \%$ & $6 \%$ & $18 \%$ & $21 \%$ \\
\hline & Malaria-specific death* & $10 \%$ & $43 \%$ & $0 \%$ & $7 \%$ & $0 \%$ & $0 \%$ & $0 \%$ & $25 \%$ & $20 \%$ & $0 \%$ & $0 \%$ & $0 \%$ & $5 \%$ & $14 \%$ \\
\hline \multirow{3}{*}{ Not oiled } & $n$ & 32 & 41 & 10 & 25 & 8 & 15 & 23 & 28 & 32 & 18 & 15 & 12 & 24 & 26 \\
\hline & $\mathrm{BS}+$ & $69 \%$ & $71 \%$ & $50 \%$ & $24 \%$ & $25 \%$ & $33 \%$ & $30 \%$ & $32 \%$ & $19 \%$ & $28 \%$ & $27 \%$ & $8 \%$ & $42 \%$ & $23 \%$ \\
\hline & Malaria-specific death* & $31 \%$ & $46 \%$ & $20 \%$ & $4 \%$ & $13 \%$ & $0 \%$ & $17 \%$ & $7 \%$ & $3 \%$ & $6 \%$ & $0 \%$ & $0 \%$ & $25 \%$ & $8 \%$ \\
\hline
\end{tabular}


Table 3: Prevalence of avian malaria in African penguins admitted to SANCCOB for rehabilitation

\begin{tabular}{|c|c|c|c|c|c|c|c|c|c}
\hline \hline Year & Total admitted & $\begin{array}{c}\text { Total } \\
\text { released }\end{array}$ & $\begin{array}{c}\text { Individual } \\
\text { bleeds }\end{array}$ & $\begin{array}{c}\text { Average bleeds } \\
\text { per bird }\end{array}$ & $\begin{array}{c}\text { Malaria } \\
\text { positive }\end{array}$ & $\begin{array}{c}\text { Apparent } \\
\text { prevalence }\end{array}$ & Total deaths & $\begin{array}{c}\text { Malaria } \\
\text { deaths }\end{array}$ & \%alaria deaths \\
\hline 2002 & 977 & 721 & 890 & 4 & 175 & $19.7 \%$ & 256 & 46 & $18 \%$ \\
\hline 2003 & 1052 & 873 & 994 & 5 & 187 & $18.8 \%$ & 179 & 43 & $24 \%$ \\
\hline 2004 & 655 & 444 & 587 & 5 & 101 & $17.2 \%$ & 211 & 20 & $9 \%$ \\
\hline 2005 & 952 & 778 & 900 & 4 & 94 & $10.4 \%$ & 174 & 33 & $19 \%$ \\
\hline 2006 & 1299 & 1118 & 1236 & 5 & 126 & $10.2 \%$ & 181 & 39 & $22 \%$ \\
\hline 2007 & 896 & 628 & 825 & 5 & 131 & $15.9 \%$ & 268 & 108 & $40 \%$ \\
\hline $2008^{*}$ & 499 & 363 & 426 & 5 & 20 & $4.7 \%$ & 136 & 3 & $2 \%$ \\
\hline $2009^{*}$ & 769 & 648 & 703 & 5 & 2 & $0.3 \%$ & 121 & 1 & $1 \%$ \\
\hline $2010^{*}$ & 905 & 686 & 839 & 4 & 11 & $1.3 \%$ & 219 & 11 & $5 \%$ \\
\hline $2011^{*}$ & 519 & 319 & 500 & 5 & 4 & $0.8 \%$ & 200 & 0 & $0 \%$ \\
\hline $2012^{*}$ & 955 & 650 & 904 & 3 & 5 & $0.6 \%$ & 304 & 3 & $1 \%$ \\
\hline $2013^{*}$ & 1021 & 687 & 895 & 3 & 20 & $2.2 \%$ & 309 & 10 & $3 \%$ \\
\hline
\end{tabular}

* Mosquito-proof netting installed over the open-air part of the facility.

\section{Discussion}

In previous studies, penguins were reported to harbour Plasmodium (in the erythrocytic stages of infection) upon admission, ${ }^{3}$ which implied that they had already been infected in the wild. In this study, Plasmodium could be detected in some penguins during rehabilitation when using blood smear analysis, which may indicate prior exposure in the wild. As observed in other studies, the BS+ cases increased in the warmer months and decreased in the colder months ${ }^{3}$, which can be attributed to the negative influence of cooler temperatures on the distribution of mosquito vectors, with a subsequent decrease in malaria infections ${ }^{22,41}$. Prior exposure to Plasmodium does not preclude the possibility of penguins being confronted with a different Plasmodium species in captivity ${ }^{4}$, given that co-infections are possible $e^{42}$ and that as expected ${ }^{25,26}$, the changes in anti-Plasmodium antibody levels did not always coincide with increases in malaria BS + cases.

If penguins survive their first infection of avian malaria, their immune system appears to be capable of reducing the number of parasites with a resulting low-level infection (premunition) resulting from survival of latent parasites. ${ }^{43}$ This premunition allows penguins to control a new infection with a rapid and intensified antibody response. Recrudescence, which is an increase in the number of latent parasites in the blood and therefore the development of symptoms, can be induced in birds with premunition by stress factors such as nutritional, environmental or migration stress. ${ }^{7}$ The rehabilitation process itself stresses penguins, which could lead to recrudescence in penguins that enter the SANCCOB facility with an existing low-level infection. ${ }^{4}$ However, if existing infections, and therefore recrudescence, were the main cause of antibody responses seen in penguins being rehabilitated, then the same increase in antibody levels should be seen throughout the year, irrespective of season. An increase in the anti-Plasmodium antibody response was, however, only observed during the warmer spring and summer months (October-March); a reduced response was observed during the colder autumn and winter months (April-September). The pattern of antibody increase and decrease did, however, shift from one year to the next because of differences in weather patterns between years. The climate along the South African west and south coasts exhibits variable temperatures and rainfall conditions (Supplementary table 1) that in turn can influence vector and parasite abundance and host exposure. ${ }^{44}$ November 2002 experienced a higher than normal rainfall which could have caused a hatch delay with an increase in mosquito populations in subsequent months ${ }^{45}$ causing a larger increase in anti-Plasmodium antibodies measured during February-May 2003 as well as an increase in malariaspecific deaths in 2003 compared to 2002 (Table 3).

In an attempt to reduce malaria infections in the facility, mosquito-proof netting was installed at the facility in 2008. A significant decrease in the prevalence of avian malaria after the installation provided conclusive evidence that avian malaria infections in the SANCCOB facility were primarily a result of new infections and not recrudescence. However, the very low numbers of penguins that contracted avian malaria in the facility after 2008 can probably be ascribed to existing infections upon admission and therefore parasite recrudescence.

New infections rely on the presence of a vector as well as a suitable avian reservoir host. It is therefore unlikely that natural infections in penguins will occur in the absence of infected wild birds. ${ }^{14}$ If African penguins are naturally infected with $P$. relictum or a subspecies thereof ${ }^{12,24}$ and have developed resistance against this species, it might be that they are exposed to possible infection by other malaria species during rehabilitation. The SANCCOB rehabilitation facility is adjacent to a large shallow freshwater lake (Rietvlei) with abundant bird life as well as large numbers of culicine mosquitoes. This scenario could facilitate host switching with resulting Plasmodium infections to which penguins are not exposed in their natural environment. ${ }^{46}$ Plasmodium spp. are known for their low specificity and broad host range which allows for host switching between different mosquito vectors as well as avian hosts. ${ }^{47}$ Host switching could also cause a parasite to undergo a change in virulence $e^{48}$ which could translate into an acute infection. Even if penguins survive these new infections during rehabilitation, they could become carriers and introduce this Plasmodium species into breeding colonies, thereby exposing the population to a new hitherto unknown Plasmodium. In future studies, it would be worthwhile to confirm, using molecular methods, ${ }^{49}$ the identity of the Plasmodium species that infect penguins during rehabilitation in comparison to those infecting breeding colonies, as well as relevant reservoir hosts.

If penguins are infected during rehabilitation, their survival may be influenced by their physical condition upon admission and thus their ability to produce an anti-Plasmodium antibody response. If the response is too low or delayed, the bird is likely to succumb ${ }^{43}$ We found no difference in the antibody reponses between penguins that survived and were released after rehabilitation versus those that died as a result 
of malaria during rehabilitation. Survival therefore did not depend on antibody response alone. The mortality results can, however, be viewed as being biased because all penguins diagnosed as malaria BS+ were treated against malaria.

Apart from large oiling events, penguins are admitted to SANCCOB as a result of chronic oiling throughout the year ${ }^{3,50}$ Oiling is one of the major human threats to penguin conservation worldwide. Oiling causes the feathers to lose their natural insulative and waterproofing properties and ingested oil can lead to internal organ damage as well as anaemia and a depression of immune function. ${ }^{50,51}$ An altered immune function could make them more susceptible to malaria infection during rehabilitation. In this study, oiling was found not to influence the ability of penguins to produce an anti-Plasmodium antibody response. A possible explanation for this finding may be that, because of the presence of conservation staff monitoring most of the African penguin breeding colonies and public awareness, penguins are brought to SANCCOB soon after oiling, and are generally strong on arrival. ${ }^{3}$ Furthermore, not oiled penguins were admitted throughout the year whilst the majority of oiled penguins were seen in winter months when there are fewer malaria infections, as diagnosed by blood smear, as well as fewer malaria-specific deaths. From this observation it can be concluded that oiling had no effect on the prevalence of malaria in African penguins that were being rehabilitated.

\section{Conclusion}

This research highlights the importance of mosquito vector control in order to control avian malaria in wild bird rehabilitation centres. Blood smear results indicated that birds are being exposed to avian malaria in the wild, but anti-Plasmodium antibody responses indicated that penguins were in all likelihood being newly infected by mosquitoes during rehabilitation. This was further confirmed by a sharp decline in malaria prevalence after vector control measures were implemented at SANCCOB in the form of mosquito netting. Further studies are needed to confirm whether penguins are confronted with a different Plasmodium species during rehabilitation than in the wild. Also, determining the source of infections will allow effective management of the disease by establishing conservation strategies to either control or prevent future infections during rehabilitation.

\section{Acknowledgements}

We thank the staff and volunteers from SANCCOB for facilitating this research. SANCCOB is supported by a wide range of donors, including the International Fund for Animal Welfare, Hans Hoheisen Charitable Trust and the National Lottery Distribution Trust Fund. N.J.P. is supported by the Sea Research Foundation (Mystic Aquarium), the Georgia Aquarium and the Leiden Conservation Foundation. This research was funded by the World Wildlife Fund (project number ZA 5020).

\section{Authors' contributions}

A.B. was responsible for methodology development, antibody analysis, curation of ELISA data, data collection, writing the initial draft and manuscript revision. H.T. was responsible for antibody analysis, curation of ELISA data and data collection. N.J.P. was responsible for blood and serum collection, data collection, curation of blood smear and malaria data, and manuscript revision. D.U.B. was responsible for conceptualisation of the project, acquisition of funding, methodology development and manuscript revision.

\section{References}

1. Crawford RJM, Altwegg R, Barham BJ, Barham PJ, Durant JM, Dyer BM, et al. Collapse of South Africa's penguins in the early 21st century. Afr J Mar Sci. 2011;33:139-156. https://doi.org/10.2989/1814232X.2011.572377

2. BirdLife International. Spheniscus demersus. The IUCN Red List of Threatened Species 2015:e.T22697810A84636189. https://doi.org/10.2305/IUCN. UK.2015.RLTS.T22697810A84636189.en

3. Parsons NJ, Underhill LG. Oiled and injured African penguins Spheniscus demersus and other seabirds admitted for rehabilitation in the Western Cape, South Africa, 2001 and 2002. Afr J Mar Sci. 2005;27:289-296. https://doi. org/10.2989/18142320509504087
4. Brossy JJ, Plös AL, Blackbeard JM, Kline A. Diseases acquired by captive penguins: What happens when they are released into the wild? Mar Ornithol. 1999;27:185-186.

5. Wolfaardt AC, Williams AJ, Underhill LG, Crawford RJM, Whittington PA. Review of the rescue, rehabilitation and restoration of oiled seabirds in South Africa, especially African penguins Spheniscus demersus and Cape gannets Morus capensis, 1983-2005. Afr J Mar Sci. 2009;31:31-54. https://doi. org/10.2989/AJMS.2009.31.1.3.774

6. Cranfield MR, Graczyk TK, Beall FB, Laleggio DM, Shaw ML Skjoldager ML. Subclinical avian malaria infections in African black-footed penguins (Spheniscus demersus) and induction of parasite recrudescence. J Wildlife Dis. 1994;30(3):372-376. https://doi.org/10.7589/0090-3558-30.3.372

7. Griner LA. Some diseases of zoo animals. Adv Vet Sci Comp Med. 1974;18:251-271.

8. Tompkins DM, Gleeson DM. Relationship between avian malaria distribution and an exotic invasive mosquito in New Zealand. J R Soc NZ. 2006;36:51-62. https://doi.org/10.1080/03014223.2006.9517799

9. Bueno MG, Lopez RPG, De Menezes RMT, Costa-Nascimento M de J, Lima GFM de C, Araújo RA de S, et al. Identification of Plasmodium relictum causing mortality in penguins (Spheniscus magellanicus) from São Paulo Zoo, Brazil. Vet Parasitol. 2010;173:123-127. https://doi.org/10.1016/j. vetpar.2010.06.026

10. Fix AS, Waterhouse C, Greiner EC, Stoskopf MK. Plasmodium relictum as a cause of avian malaria in wild-caught Magellanic penguins (Spheniscus magellanicus). J Wildl Dis. 1988;24:610-619. https://doi.org/10.7589/00903558-24.4.610

11. Vanstreels RET, Da Silva-Filho RP, Kolesnikovas CKM, Bhering RCC, Ruoppolo $\mathrm{V}$, Epiphanio $\mathrm{S}$, et al. Epidemiology and pathology of avian malaria in penguins undergoing rehabilitation in Brazil. Vet Res. 2015;46, Art. \#30, 12 pages. https://doi.org/10.1186/s13567-015-0160-9

12. Fantham HB, Porter A. On a Plasmodium (Plasmodium relictum var. spheniscidae, n. var.), observed in four species of penguins. Proc Zool Soc Lond. 1944;114:279-292. https://doi.org/10.1111/j.1096-3642.1944. tb00222.x

13. Graczyk TK, Brossy JJ, Plös A, Stoskopf MK. Avian malaria seroprevalence in jackass penguins (Spheniscus demersus) in South Africa. J Parasitol. 1995;81(5):703-707. https://doi.org/10.2307/3283958

14. Beier JC, Stoskopf MK. The epidemiology of avian malaria in black-footed penguins (Spheniscus demersus). J Zoo Anim Med. 1980;11:99-105. https://doi.org/10.2307/20094486

15. Wikelski M, Foufopoulos J, Vargas H, Snell H. Galápagos birds and diseases: Invasive pathogens as threats for island species. Ecol Soc. 2004;9(1), Art. \#5, 10 pages. https://doi.org/10.5751/ES-00605-090105

16. National Research Council (US) Committee on the Scientific Bases for the Preservation of the Hawaiian Crow. In: The scientific bases for the preservation of the Hawaiian crow. Washington DC: National Academic Press; 1992. https://doi.org/10.17226/2023

17. Freed LA, Cann RL, Goff ML, Kuntz WA, Bodner GR. Increase in avian malaria at upper elevation in Hawai'i. The Condor. 2005;107(4):753-764. https://doi. org/10.1650/7820.1

18. Levin II, Adkesson MJ, Evans M, Rettke CK, Parker PG. No evidence for Galapagos Plasmodium lineage arriving via Humboldt Current seabirds. Pacific Conserv Biol. 2014;20(1):37-40.

19. Croxall JP. Southern ocean environmental changes: Effects on seabird, seal and whale populations. Phil Trans R Soc Lond B. 1992;338:319-328. https:// doi.org/10.1098/rstb.1992.0152

20. Heard MJ, Smith KF, Ripp KJ, Berger M, Chen J, Dittmeier J, et al. The threat of disease increases as species move toward extinction. Conserv Biol. 2013;27:1378-1388. https://doi.org/10.1111/cobi.12143

21. Grilo ML, Vanstreels RET, Wallace R, Carcía-Párraga D, Braga ÉM, Chitty J, et al. Malaria in penguins - Current perceptions. Avian Pathol. 2016;45:393407. https://doi.org/10.1080/03079457.2016.1149145

22. Atkinson CT, Van Riper C. Pathogenicity and epizootiology of avian haematozoa: Plasmodium, Leucocytozoon, and Haemoproteus. In: Loye JE, Zuk M, editors. Bird-parasite interactions ecology, evolution and behavior. Oxford: Oxford University Press; 1991. p. 20-48. 
23. Graczyk TK, Cranfield MR, Shiff CJ. ELISA method for detecting antiPlasmodium relictum and anti-Plasmodium elongatum antibody in infected duckling sera using Plasmodium falciparum antigens. J Parasitol. 1993;79:879-885. https://doi.org/10.2307/3283726

24. Brossy J-J. Malaria in wild and captive jackass penguins Spheniscus demersus along the southern African coast. Ostrich. 1992;63:10-12. https:// doi.org/10.1080/00306525.1992.9634174

25. Sturrock HJW, Tompkins DM. Avian malaria (Plasmodium spp) in yelloweyed penguins: Investigating the cause of high seroprevalence but low observed infection. N Z Vet J. 2007;55(4):158-160. https://doi.org/10.108 0/00306525.1992.9634174

26. Palmer JL, McCutchan TF, Vargas FH, Deem SL, Cruz M, Hartman DA, et al. Seroprevalence of malarial antibodies in Galapagos penguins (Spheniscus mendiculus). J Parasitol. 2013;99(5):770-776. https://doi.org/10.1645/1257.1

27. Graczyk TK, Cranfield MR, Skjoldager ML, Shaw ML. An ELISA for detecting anti-Plasmodium spp. antibodies in African black-footed penguins (Spheniscus demersus). J Parasitol. 1994;80:60-66. https://doi. org $/ 10.2307 / 3283346$

28. Young JF, Hockmeyer WT, Gross M, Ballou WR, Wirtz RA, Trosper JH, et al. Expression of Plasmodium falciparum circumsporozoite proteins in Escherichia coli for potential use in a human malaria vaccine. Science. 1995;228:958-962. https://doi.org/10.2307/3283346

29. Santoro F, Cochrane AH, Nussenzweig V, Nardin EH, Nussenzweig RS, Gwadz RW, et al. Structural similarities among the protective antigens of sporozoites from different species of malaria parasites. J Biol Chem. 1983;258:33413345 .

30. Cochrane AH, Santoro F, Nussenzweig V, Gwadz RW, Nussenzweig RS. Monoclonal antibodies identify the protective antigens of sporozoites of Plasmodium knowlesi. Proc Natl Acad Sci. 1982;79:5651-5655. https://doi. org/10.1073/pnas.79.18.5651

31. Krettli AU, Rocha EMM, Lopes JD, Carneio CRW, Kamboj KK, Cochrane AH, et al. Circumsporozoite protein of Plasmodium gallinaceum characterized by monoclonal antibodies. Parasite Immunol. 1988;10:523-533. https://doi. org/10.1111/j.1365-3024.1988.tb00240.x

32. Ballou WR, Rothbard J, Wirtz RA, Gordon DM, Williams JS, Gore RW, et al. Immunogenicity of synthetic peptides from circumsporozoite protein of Plasmodium falciparum. Science. 1985;228:996-999. https://doi. org/10.1126/science.2988126

33. Botes A. Immunological and epidemiological investigations in South African ostriches and penguins [PhD dissertation]. Stellenbosch: Stellenbosch University; 2003

34. Klotz IM, Heiney RE. A new method for the introduction of thiol groups into proteins. J Am Chem Soc. 1959;81:3802-3803. https://doi.org/10.1021/ ja01523a083

35. Rector ES, Schwenk RJ, Tse KS, Sehon AH. A method for the preparation of protein-protein conjugates of predetermined composition. J Immunol Methods. 1978;24:321-336. https://doi.org/10.1016/0022-1759(78)90135-7

36. Yoshitake S, Imagawa M, Ishikawa E, Ntitsu Y, Urushizaki I, Nishiura M, et al. Mild and efficient conguation of rabbit Fab' and horseradish peroxidase using a maleimide compound and its use for enzyme immunoassay. J Biochem. 1982;92:1413-1424. https://doi.org/10.1093/oxfordjournals.jbchem.a134065
37. Partis MD, Griffiths DG, Roberts GS, Beechey RB. Cross-linking of protein by $\omega$-maleimido alkanoyl N-hydroxysuccinimido esters. J Protein Chem. 1983;2:263-277. https://doi.org/10.1007/BF01025358

38. Hashida S, Imagawa M, Inoue S, Ruan K, Ishikawa E. More useful maleimide compounds for the conjugation of Fab' to horseradish peroxidase through thiol groups in the hinge. J Appl Biochem. 1984;6:56-63.

39. Harris C, Burgers C, Miller J, Rawoot F. O-and H-Isotope record of Cape Town rainfall from 1996 to 2008, and its application to recharge studies of Table Mountain groundwater, South Africa. S Afr J Geol. 2010;113:33-56. https:// doi.org/10.2113/gssajg.113.1.33

40. Grim KC, Van der Merwe E, Sullivan M, Parsons N, McCutchan TF, Cranfield M. Plasmodium juxtanucleare associated with mortality in black-footed penguins (Spheniscus demersus) admitted to a rehabilitation centre. J Zoo Wildl Med. 2003;34:250-255. https://doi.org/10.1638/02-070

41. Atkinson CT. Hemosporidiosis. In: Ciganovich EA, Friend M, Franson JC, editors. Field manual of wildlife diseases general field procedures and diseases of birds. Madison, WI: USGS, Biological Resources Division, National Wildlife Health Center; 2001. p. 193-199.

42. Silveira P, Belo NO, Lacorte GA, Kolesnikovas CKM, Vanstreels MS, Catão-Dias $\mathrm{JL}$, et al. Parasitological and new molecular-phologenetic characterization of the malaria parasite Plasmodium tejerai in South American penguins. Parasitol Int. 2013;62:165-171. https://doi.org/10.1016/j.parint.2012.12.004

43. Seed TM, Manwell RD. Plasmodia of birds. In: Kreier JP, editor. Parasitic protozoa. Vol III. New York: Academic Press; 1977. p. 311-357.

44. Loiseau C, Harrigan RJ, Robert A, Bowie RCK, Thomassen HA, Smith TB, et al. Host and habitat specialization of avian malaria in Africa. Mol Ecol. 2012;21:431-441. https://doi.org/10.1111/j.1365-294X.2011.05341.x

45. Okanga S, Cumming GS, Hockey PAR. Avian malaria prevalence and mosquito abundance in the Western Cape, South Africa. Malaria J. 2013;12, Art. \#370, 14 pages. https://doi.org/10.1186/1475-2875-12-370

46. Njabo KY, Cornel AJ, Bonneaud C, Toffelmier E, Sehgal RNM, Valkiūnas $G$, et al. Nonspecific patterns of vector, host and avian malaria parasite associations in a central African rainforest. Mol Ecol. 2011;20:1049-1061. https://doi.org/10.1111/j.1365-294X.2010.04904.X

47. Martínez-de la Puente J, Martínez J, Rivero-de Aguilar J, Herrero J, Merino S On the specificity of avian blood parasites: Revealing specific and generalist relationships between haemosporidians and biting midges. Mol Ecol. 2011;20:3275-3287. https://doi.org/10.1111/j.1365-294X.2011.05136.X

48. Bensch S, Stjernman M, Hasselquist D, Östman Ö, Hansson B, Westerdah $H$, et al. Host specificity in avian blood parasites: A study of Plasmodium and Haemoproteus mitochondrial DNA amplified from birds. Proc R Soc Lond B. 2000;267:1583-1589. https://doi.org/10.1098/rspb.2000.1181

49. Bensch S, Hellgren 0, Pérez-Tris J. MalAvi: A public database of malaria parasites and related haemosporidians in avian hosts based on mitochondrial cytochrome $b$ lineages. Mol Ecol. 2009;9:1353-1358. https://doi. org/10.1111/j.1755-0998.2009.02692.x

50. Nel DC, Crawford RJM, Parsons N. The conservation status of oiling on the African penguin. In: Nel DC, Whittington PA, editors. Rehabilitation of oiled African penguins: A conservation success story. Cape Town: BirdLife South Africa and the Avian Demography Unit; 2003. p. 1-7.

51. Briggs KT, Yoshida SH, Gershwin ME. The influence of petrochemicals and stress on the immune system of seabirds. Regul Toxicol Pharmacol. 1996;23:145-155. https://doi.org/10.1006/rtph.1996.0036 